\title{
Is working in a cold environment associated with musculoskeletal complaints 7-8 years later? A longitudinal analysis from the Tromsø Study
}

\author{
Erlend Hoftun Farbu ${ }^{1}\left[\right.$. Anje Christina Höper ${ }^{1,2} \cdot$ Tormod Brenn $^{1} \cdot$ Morten Skandfer $^{1}$
}

Received: 26 March 2020 / Accepted: 30 October 2020 / Published online: 23 November 2020

(c) The Author(s) 2020

\begin{abstract}
Objective Exposure to a cold environment at work is associated with a higher prevalence of musculoskeletal pain and chronic pain in cross-sectional studies. This study aims to determine the association between working in a cold environment $\geq 25 \%$ of the time and musculoskeletal complaints (MSC) 7-8 years later.

Methods We followed participants from the sixth survey (Troms $\varnothing 6,2007-2008$ ) to the seventh survey (Troms $\emptyset 7,2015-$ 2016) of the Troms $\varnothing$ Study. Analyses included 2347 men and women aged 32-60 years who were not retired and not receiving full-time disability benefits in Troms $\emptyset$ 6. Three different binary outcomes were investigated in Troms $\varnothing$ : any MSC, severe MSC, and MSC in $\geq 3$ anatomical regions. We excluded participants with severe MSC, MSC in $\geq 3$ regions, or missing values in Troms $\varnothing 6$. The association between working in a cold environment and future MSC were examined using Poisson regression and adjusted for age, sex, number of moderate MSC, education, physical activity at work, smoking status, body mass index, and self-reported health in Troms $\varnothing 6$.

Results 258 participants reported to work in a cold environment $\geq 25 \%$ of the time in Troms $\varnothing 6$. They had an increased risk of having any MSC in Troms $\emptyset$ (incidence rate ratio 1.15; 95\% confidence interval 1.03-1.29). There was no significantly increased risk of severe MSC or MSC in $\geq 3$ regions.

Conclusion Working in a cold environment was associated with future MSC, but not with future severe MSC or future MSC in $\geq 3$ regions.
\end{abstract}

Keywords Musculoskeletal pain $\cdot$ Musculoskeletal complaints $\cdot$ Cold environment $\cdot$ Epidemiology $\cdot$ Cold temperature

\section{Introduction}

Even moderately cold temperatures can cause stress to the human body and increase mortality (Gasparrini et al. 2015). Exposure to a cold environment at work has been suggested as a risk factor or aggravator of different health complaints, such as musculoskeletal pain and symptoms from skin, the

Electronic supplementary material The online version of this article (https://doi.org/10.1007/s00420-020-01606-6) contains supplementary material, which is available to authorized users.

Erlend Hoftun Farbu

erlend.h.farbu@uit.no

1 Department of Community Medicine, UiT-The Arctic University of Norway, Troms $\varnothing$, Norway

2 Department of Occupational and Environmental Medicine, University Hospital of North Norway, Troms $\varnothing$, Norway respiratory system, and the cardiovascular system (Makinen and Hassi 2009).

A cold working environment is defined as a temperature below $10{ }^{\circ} \mathrm{C}$ (ISO 15743:2008 Ergonomics of the thermal environment-cold workplaces—risk assessment and managment 2008), but cold stress might be present even at higher temperatures in the workplace (Bang et al. 2005). In addition, ambient temperature is only one of many factors that determine a worker's heat loss. Clothing, air movement, contact with cold surfaces and liquids, and the amount of heat produced by the work can also have an impact on a worker's thermal balance and thereby possibly lead to health complaints.

Low back and neck pain are a major cause of disability-adjusted life years (Murray et al. 2012). Furthermore, chronic pain is strongly associated with future disability pension, due to both musculoskeletal and other disorders (Haukka et al. 2015; Saastamoinen et al. 2012). Several 
cross-sectional studies have found that working in a cold environment or feeling cold is associated with a higher prevalence of pain among slaughterhouse, construction, seafood industry, and storehouse workers, as well as in the general population. The association has also been found for musculoskeletal locations such as the wrist, back, neck, and shoulder (Aasmoe et al. 2008; Dovrat and Katz-Leurer 2007; Farbu et al. 2019; Pienimaki 2002; Skandfer et al. 2014). In a cohort of 134,754 male Swedish construction workers, there was a higher prevalence of musculoskeletal pain in geographical regions with lower mean temperatures (Burstrom et al. 2013). Some studies have reported a higher incidence of tendinopathies and associated disorders in colder environments (Kurppa et al. 1991; Milgrom et al. 2003). However, there is a need for more prospective studies investigating exposure to a cold environment at work as a risk factor for musculoskeletal pain.

Our previous cross-sectional study from the sixth survey of the Troms $\varnothing$ Study (Troms $\emptyset$ 6) found that working in a cold environment $\geq 25 \%$ of the time was associated with chronic pain lasting 3 months or longer (Farbu et al. 2019). In the consecutive, seventh survey of the Tromsø Study (Troms $\varnothing 7$ ) the questions concerning chronic pain and anatomical sites were replaced with a computerised system, in which participants pointed and clicked on a digital mannequin to show affected sites, combined with questions. Thus, answers in Troms $\varnothing 6$ and Troms $\varnothing 7$ are not directly comparable. Therefore, the outcomes in this prospective analysis are based on another set of questions that were phrased identically in both surveys. However, as these questions assessed both pain and/ or stiffness in the same question, we termed it "musculoskeletal complaints" (MSC).

This study aims to determine the association between working in a cold environment $\geq 25 \%$ of the time and MSC $7-8$ years later.

\section{Methods}

\section{Population: the Tromsø Study}

The Troms $\varnothing$ Study is a prospective cohort study consisting of seven surveys carried out from 1974 to 2016. We used the data from Troms $\varnothing 6$ (2007-2008) as the baseline and that from Troms $\varnothing 7$ (2015-2016) as follow-up (Jacobsen et al. 2012). The surveys consist of a physical examination and questionnaires. As the risk of MSC is likely to decrease after retirement, we excluded all participants who were retired, older than 60 , or receiving a fulltime disability pension at the time of Troms $\varnothing 6$ (Neupane et al. 2018). Finally, we excluded all participants with missing values in Troms $\varnothing 6$ (Fig. 1). The Regional Committee of Research Ethics approved Troms $\varnothing 6$ and 7 and this particular analysis.

\section{Exposure and confounders}

The question "Do you work outdoors or in cold buildings (e.g. storage/industry buildings) at least $25 \%$ of the time?" (Yes/No) from Troms $\varnothing 6$ was the exposure of interest. Troms $\varnothing$ has a coastal climate; the outdoor temperature is below $10{ }^{\circ} \mathrm{C}$ for most of the year and seldom falls below $-10{ }^{\circ} \mathrm{C}$ [Weather statistics for Troms $\varnothing$ observation site, Troms $\varnothing$ (Troms) 2018]. In Troms $\varnothing 7$ there was no measure for cold exposure.

Information on age and education was taken from Troms $\emptyset$ 6 . The degree of physical activity at work was assessed with the question "If you have paid or unpaid work, which statement describes your work best?", with four response alternatives: mostly sedentary, requires a lot of walking, requires a lot of walking and lifting, and heavy manual labour. Smoking status was categorised as current, former, and never smoker. Body mass index (BMI) was calculated from height and weight measures at the Troms $\varnothing 6$ physical examination. Self-reported health was assessed with the question "How do you in general consider your own health to be?", with five response alternatives: excellent, good, neither good nor bad, bad, and very bad. Due to few respondents reporting bad and very bad, the categories were merged with "neither good nor bad".

\section{Outcomes}

In both Troms $\varnothing 6$ and Troms $\varnothing 7$, information on MSC was collected with the question "During the last year have you been affected by pain and/or stiffness in muscles or joints lasting at least 3 months?" with a list of six different anatomical regions: neck or shoulder, upper back, lumbar back, hip or leg, arm or hand, and other. For each site there were three alternatives: no, moderately, or severely. We investigated three different binary outcomes: any MSC, severe MSC, and MSC in $\geq 3$ regions. Those reporting moderate or severe MSC at one or more regions were categorised as having "any MSC". Participants who reported severe MSC at any of the six regions were categorised as "severe MSC". For the third binary outcome, we counted the number of regions with MSC, regardless of severity, and categorised them into $0-2$ regions and $\geq 3$ regions. We excluded all those who reported severe MSC or MSC in $\geq 3$ regions in Troms $\varnothing$ 6.

\section{Statistical analyses}

Pearson chi-square was used to test differences in prevalence, and $t$ test was used for age. We used Poisson regression with robust variance to perform three different analyses for the three binary outcomes; any MSC, severe MSC, and 
Fig. 1 Flow chart presenting number of subjects invited to Troms $\varnothing 6$, those who participated in Troms $\varnothing 6$ and in Troms $\varnothing 7$, and those excluded and included in the present analysis

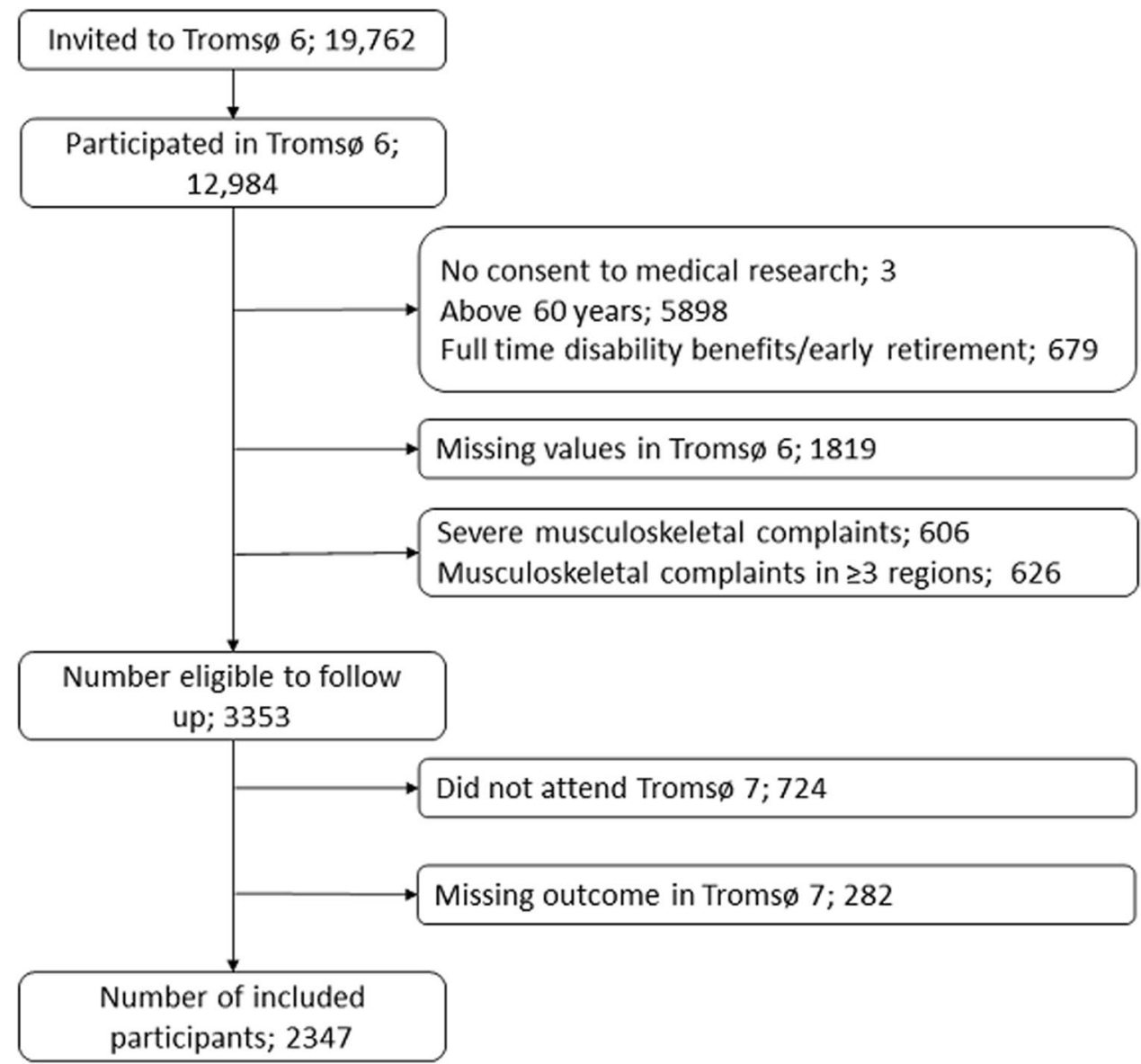

MSC in $\geq 3$ regions. Poisson regression is recommended when analysing binary outcomes with high prevalence. The effect estimate is incidence rate ratio (IRR) and can be interpreted as relative risk (Zou 2004). All statistical analyses were performed in Stata MP 15.

\section{Sensitivity analysis}

A large proportion of participants were excluded due to missing values in Troms $\varnothing 6$ (Fig. 1). As this could introduce bias, we performed multiple imputation with chained equations. We included the original questions about MSC and all the variables included in the main analysis. To increase the predictive power, we included dichotomous questions about chronic pain from Troms $\varnothing 6$ and Troms $\varnothing 7$, as well as pain sites from Troms $\varnothing 7$. Due to perfect prediction, we used the augment option and imputed 100 datasets. To make the IRRs from the imputed regression models comparable to the IRRs from the main analysis, we included an interaction term between having severe MSC or MSC in $\geq 3$ regions in Troms $\varnothing 6$ and working in a cold environment $\geq 25 \%$ of the time in the regression analysis on the imputed datasets.

To investigate possible confounding by occupational factors, we conducted sensitivity analyses using occupational codes obtained from the NAV State Register of Employers and Employees (NREE), which is administrated by Statistics Norway. Employers are required to register all those employed for at least 7 days and who will likely have an average of more than 4 h' work per week in the NREE. Each employee is registered with an industrial classification code using the Norwegian coding system, STYRK-98. The 4 first digits of this system are similar to those in the International Standard Classification of Occupations 88. We used the unique 11-digit identification number assigned to all individuals living in Norway to link the NREE with the data from the Troms $\varnothing$ Study. The NREE was not complete at the time of Troms $\varnothing 6$; therefore, we restricted sensitivity analyses to the subsample of participants with an existing occupational code in the NREE in 2007. For those missing a code in 2007 but with an existing code in 2008, we used the one from 2008. To assess the possible confounding effect of occupation on the association between working in a cold environment and MSC, we ran three different logistic regression analyses: (1) a model identical to that in the main analysis; (2) a model adjusted for the 10 major occupational groups in the International Standard Classification of Occupations 88; (3) a mixed-effects logistic model with a random intercept for each 4-digit occupational code. 


\section{Results}

Of the 2347 participants, 258 reported working in a cold environment $\geq 25 \%$ of the time in Troms $\varnothing 6$. The latter participants reported more moderate MSC in Troms $\varnothing$ 6, had less education, were more physically active at work, were more often smokers or former smokers, and a higher BMI than those working in a cold environment $<25 \%$ of the time. They also had poorer self-reported health. There were no significant differences in age at the time of Troms $\varnothing 6$ between those working in a cold environment $\geq 25 \%$ of the time and those who did not (Table 1).

\section{Musculoskeletal complaints}

In Troms $\varnothing 7$, those who reported working in a cold environment $\geq 25 \%$ of the time in Troms $\emptyset 6$ had a higher prevalence of both moderate and severe MSC (Table 2). The prevalence of participants with MSC in 1-2 and $\geq 3$ regions was higher in the exposed group. These differences were evident among those who had no MSC in Troms $\varnothing$ 6, while there were no significant differences among those reporting moderate MSC in Tromsø 6.

Those working in a cold environment $\geq 25 \%$ of the time had a significantly increased risk of any MSC in Troms $\varnothing$ 7 , after adjustment for age, sex and number of moderate MSC in Troms $\varnothing 6$ [IRR 1.13; 95\% confidence interval (CI)
Table 1 Characteristics of the study population in Troms $\varnothing 6$ (baseline)

\begin{tabular}{|c|c|c|c|c|c|}
\hline & \multicolumn{5}{|c|}{ Working in a cold environment $\geq 25 \%$ of the time } \\
\hline & \multicolumn{2}{|c|}{ No, $n=2089$} & \multicolumn{2}{|c|}{ Yes, $n=258$} & \multirow{2}{*}{$\begin{array}{l}t / \chi^{2} \\
p\end{array}$} \\
\hline & $n$ & $\%$ & $n$ & $\%$ & \\
\hline $\operatorname{Age}^{\mathrm{a}}$ & 47.1 & 6.9 & 46.7 & 6.9 & 0.396 \\
\hline \multicolumn{6}{|l|}{ Sex } \\
\hline Female & 1041 & 50 & 52 & 20 & \\
\hline Male & 1048 & 50 & 206 & 80 & $<0.001$ \\
\hline \multicolumn{6}{|l|}{ Number of moderate musculoskeletal complaints } \\
\hline 0 & 1260 & 60.3 & 123 & 47.7 & \\
\hline 1 & 483 & 23.1 & 66 & 25.6 & \\
\hline 2 & 346 & 16.6 & 69 & 26.7 & $<0.001$ \\
\hline \multicolumn{6}{|l|}{ Education } \\
\hline Primary/secondary & 154 & 7.4 & 61 & 23.6 & \\
\hline Technical school & 370 & 17.7 & 107 & 41.5 & \\
\hline High school & 196 & 9.4 & 37 & 14.3 & \\
\hline College/university less than 4 years & 559 & 26.7 & 41 & 15.9 & \\
\hline College/university 4 years or more & 810 & 38.8 & 12 & 4.7 & $<0.001$ \\
\hline \multicolumn{6}{|l|}{ Physical activity at work } \\
\hline Mostly sedentary work & 1387 & 66.4 & 33 & 12.8 & \\
\hline Work that requires a lot of walking & 474 & 22.7 & 71 & 27.5 & \\
\hline Work that requires a lot of walking and lifting & 223 & 10.7 & 125 & 48.5 & \\
\hline Heavy manual labour & 5 & 0.2 & 29 & 11.2 & $<0.001$ \\
\hline \multicolumn{6}{|l|}{ Smoking status } \\
\hline Current & 303 & 14.5 & 57 & 22.1 & \\
\hline Former & 745 & 35.7 & 101 & 39.1 & \\
\hline Never & 1041 & 49.8 & 100 & 38.8 & 0.001 \\
\hline \multicolumn{6}{|l|}{ Body mass index } \\
\hline Under and normal weight $\left(<25 \mathrm{~kg} / \mathrm{m}^{2}\right)$ & 892 & 42.7 & 85 & 32.9 & \\
\hline Overweight $\left(\geq 25\right.$ and $\left.<30 \mathrm{~kg} / \mathrm{m}^{2}\right)$ & 886 & 42.4 & 131 & 50.8 & \\
\hline Obese $\left(\geq 30 \mathrm{~kg} / \mathrm{m}^{2}\right)$ & 311 & 17.9 & 42 & 16.3 & 0.01 \\
\hline \multicolumn{6}{|l|}{ Self-reported health } \\
\hline $\mathrm{Bad} /$ very bad/neither good nor bad & 231 & 11.1 & 40 & 15.5 & \\
\hline Good & 1193 & 57.1 & 171 & 66.3 & \\
\hline Excellent & 665 & 31.8 & 47 & 18.2 & $<0.001$ \\
\hline
\end{tabular}

${ }^{\mathrm{a}}$ Numbers are mean and standard deviation for age 
Table 2 Participants having no or moderate musculoskeletal complaints (MSC) in Troms $\varnothing 6$, and severity of MSC and MSC in $0,1-2$, or $\geq 3$ anatomical regions in Tromsø 7

\begin{tabular}{|c|c|c|c|c|c|c|c|c|c|c|}
\hline \multirow[t]{4}{*}{ Troms $\emptyset 7$} & \multicolumn{5}{|c|}{ No MSC in Tromsø 6} & \multicolumn{5}{|c|}{ Moderate MSC in Troms $\emptyset 6$} \\
\hline & \multicolumn{5}{|c|}{$\begin{array}{l}\text { Working in a cold environment } \geq 25 \% \text { of the } \\
\text { time }\end{array}$} & \multicolumn{5}{|c|}{$\begin{array}{l}\text { Working in a cold environment } \geq 25 \% \text { of } \\
\text { the time }\end{array}$} \\
\hline & \multicolumn{2}{|c|}{$\begin{array}{l}\text { No } \\
n=1260\end{array}$} & \multicolumn{2}{|c|}{$\begin{array}{l}\text { Yes } \\
n=123\end{array}$} & \multirow{2}{*}{$\begin{array}{l}\chi^{2} \\
p\end{array}$} & \multicolumn{2}{|c|}{$\begin{array}{l}\text { No } \\
n=829\end{array}$} & \multicolumn{2}{|c|}{$\begin{array}{l}\text { Yes } \\
n=135\end{array}$} & \multirow{2}{*}{$\begin{array}{l}\chi^{2} \\
p\end{array}$} \\
\hline & $n$ & $\%$ & $N$ & $\%$ & & $n$ & $\%$ & $n$ & $\%$ & \\
\hline \multicolumn{11}{|c|}{ Severity of MSC } \\
\hline No & 697 & 55.3 & 53 & 43.1 & & 251 & 30.3 & 39 & 28.9 & \\
\hline Moderate & 500 & 39.7 & 62 & 50.4 & & 471 & 56.8 & 78 & 57.8 & \\
\hline \multirow[t]{2}{*}{ Severe } & 63 & 5.0 & 8 & 6.5 & & 107 & 12.9 & 18 & 13.3 & \\
\hline & & & & & 0.034 & & & & & 0.947 \\
\hline \multicolumn{11}{|c|}{ Number of MSC } \\
\hline 0 & 697 & 55.3 & 53 & 43.1 & & 251 & 30.3 & 39 & 28.9 & \\
\hline $1-2$ & 420 & 33.3 & 48 & 39.0 & & 364 & 43.9 & 61 & 45.2 & \\
\hline$\geq 3$ & 143 & 11.4 & 22 & 17.9 & & 214 & 25.8 & 35 & 25.9 & \\
\hline & & & & & 0.017 & & & & & 0.943 \\
\hline
\end{tabular}

1.02-1.25] (Table 3). This association was slightly stronger after further adjustment for education, physical activity at work, smoking, BMI, and self-reported health in Troms $\varnothing 6$ (IRR $1.1595 \%$ CI 1.03-1.29).

In the model using severe MSC as an outcome, those working in a cold environment $\geq 25 \%$ of the time had no significantly increased risk of MSC after adjustment for age, sex, and number of moderate MSC in Troms $\varnothing 6$ (Table 3).

The risk of $\mathrm{MSC}$ in $\geq 3$ regions was higher for those working in a cold environment $\geq 25 \%$ of the time in the model adjusted for age, sex, and number of moderate MSC in Troms $\varnothing 6$ (IRR 1.27; 95\% CI 0.98-1.64). However, the association was not significant, and further adjustment attenuated the association (IRR 1.11; 95\% CI 0.83-1.49).

The results from the analysis using imputed data gave similar results. In the full model, those working in a cold environment $\geq 25 \%$ of the time had an increased risk of any MSC (IRR 1.12; 95\% CI 1.03-1.22) and no increased risk of severe MSC (IRR 0.77; 95\% CI 0.69-1.38) or MSC in $\geq 3$ regions (IRR 1.08; 95\% CI 0.88-1.32) (Supplementary Table 1).

\section{Sensitivity analyses with occupational codes}

The logistic regression model that adjusted for the 10 major occupational groups did not substantially alter the strength of the association when all other covariates were included, nor did the mixed-effects model with a random intercept for each 4-digit occupational code (Supplementary Table 2). Supplementary Table 3 shows the different occupations in Troms $\varnothing 6$ for those working in a cold environment $\geq 25 \%$ of the time.
Table 3 Incidence rate ratio's (IRR) for any musculoskeletal complaints (MSC), severe MSC, and MSC in $\geq 3$ anatomical regions in Troms $\emptyset 7$

\begin{tabular}{|c|c|c|c|c|c|c|c|c|c|}
\hline & \multicolumn{2}{|c|}{$\begin{array}{l}\text { Working in a cold } \\
\text { environment }<25 \% \\
\text { of the time } \\
n=2089\end{array}$} & \multicolumn{7}{|c|}{$\begin{array}{l}\text { Working in a cold environment } \geq 25 \% \text { of the time } \\
n=258\end{array}$} \\
\hline & \multirow[b]{2}{*}{$n$} & \multirow[b]{2}{*}{ IRR } & \multicolumn{4}{|c|}{ Crude $^{\mathrm{a}}$} & \multicolumn{3}{|c|}{ Fully adjusted model ${ }^{\mathrm{b}}$} \\
\hline & & & $n$ & IRR & CI & & IRR & CI & \\
\hline Any MSC & 1141 & Ref & 166 & 1.13 & 1.02 & 1.25 & 1.15 & 1.03 & 1.29 \\
\hline Severe MSC & 170 & - & 26 & 1.14 & 0.76 & 1.70 & 0.95 & 0.60 & 1.48 \\
\hline $\begin{array}{l}\text { MSC in } \geq 3 \text { ana- } \\
\text { tomical regions }\end{array}$ & 357 & - & 57 & 1.27 & 0.98 & 1.64 & 1.11 & 0.83 & 1.49 \\
\hline
\end{tabular}

${ }^{a}$ Adjusted for age, sex, and number of moderate MSC in Troms $\varnothing 6$

${ }^{\mathrm{b}}$ Adjusted for age, sex, number of moderate MSC, education, physical activity at work, smoking status, body mass index, and self-reported health in Troms $\emptyset 6$ 


\section{Discussion}

\section{Key findings}

This is the first prospective study of working in a cold environment as a risk factor for future MSC in the general working population. Those working in a cold environment $\geq 25 \%$ of the time had a significantly increased risk of experiencing any MSC with a duration of $\geq 3$ months 7-8 years later. This association remained significant even after adjustment for baseline characteristics of age, sex, number of moderate MSC, education, physical activity at work, smoking, BMI, and self-reported health in Troms $\varnothing 6$. The risk of severe MSC or MSC in $\geq 3$ regions was not significantly higher for those working $\geq 25 \%$ of the time in a cold environment.

One previous study found an increased incidence of Achilles paratendinitis among recruits who completed their basic training in winter compared to summer (Milgrom et al. 2003). Another study of meat-house workers noted that the only noticeable difference between two groups with different incidences of tenosynovitis was a colder workplace environment (Kurppa et al. 1991). Other cross-sectional studies have found a higher prevalence of musculoskeletal pain among workers exposed to a cold environment. The studied populations were storehouse workers, construction workers, mine workers and seafood industry workers, and the general working population (Aasmoe et al. 2008; Burstrom et al. 2012; Dovrat and Katz-Leurer 2007; Farbu et al. 2019; Skandfer et al. 2014). In our previous study, we found an association between working in a cold environment and chronic pain at $\geq 3$ anatomical sites (Farbu et al. 2019), but in the current study, we did not find any significant increased risk of MSC in $\geq 3$ regions. The higher resolution of the outcome measure in our previous study could explain some of this difference, as the previous study investigated 14 different sites with chronic pain versus 6 regions with MSC in the current study, which means that a participant with pain in the neck, shoulder, and arm would have been classified differently in the two studies. However, since the outcomes in this study concern how much the participants are "affected by pain and/or stiffness", and we do not know how many have stiffness without pain, direct comparison with our earlier research is precarious.

Among participants without MSC in Troms $\varnothing$ 6, those working $\geq 25 \%$ of the time in a cold environment had a significantly higher prevalence of MSC in Troms $\varnothing 7$. However, there was no such difference among those with moderate MSC in Troms $\varnothing$ 6. This indicates that working in a cold environment could contribute to developing MSC, but not aggravate already existing MSC. This is consistent with the lack of significant associations for severe MSC and MSC in $\geq 3$ regions. One explanation could be that those working in a cold environment are more prone to transient MSC, like tendinopathies, which often have quite a good prognosis even if left untreated (Smidt et al. 2002).

There was a high prevalence of MSC in the present study, with over $50 \%$ of the study population reporting moderate or severe MSC in Troms $\varnothing 7$. This high prevalence could indicate that any MSC includes complaints that are more of a nuisance; not MSC that have a serious impact on quality of life. In this regard, severe MSC or having pain in $\geq 3$ regions are likely more discriminant. In Troms $\varnothing 7$, the prevalences of severe MSC and MSC in $\geq 3$ regions were $11 \%$ and $18 \%$, respectively. Nevertheless, pain is a strong risk factor for more pain, and even moderate pain is associated with a lack of labour force participation and absenteeism (Bergman et al. 2002; Elliott et al. 2002; Langley et al. 2010).

Self-reported working in a cold environment $\geq 25 \%$ of the time is an imprecise measure of cold exposure. Even though the question used to assess exposure specified outdoors, cold stores, or industry buildings, participants might have answered that they worked in a cold building simply because they considered their office to be cold. Some participants with occupations that are most likely performed in an office reported working in a cold environment, i.e. executive officers and customer service officers in banking (Supplementary Table 3). Consequently, we are at risk of classifying participants with minimal exposure to cold environments as exposed, which may have led us to underestimate the effect of working in a cold environment. On the other hand, our previous cross-sectional analysis showed that feeling cold was strongly associated with chronic pain (Farbu et al. 2019). Thus, the measure of cold exposure in this study might, to some degree, represent perceived thermal stress or an underlying trait that increases the likelihood of both feeling cold and developing MSC. Thus, misclassification of exposure might lead to both over- and underestimation of the effect. It should be mentioned that the high number of childcare workers who reported working in a cold environment is plausible, as most kindergarten classes in Norway spend some hours outdoors every day (Supplementary Table 3).

\section{Plausible causal pathway}

Few plausible causal pathways between cold environments and MSC have been suggested in the literature. One possible pathway is the acute effects of cold environments on physiological function. Indeed, the capacity of a muscle to develop force and contraction velocity are reduced as muscular temperature lowers (Racinais and Oksa 2010), and increased co-activation of antagonist muscle can also occur, indicating poorer neuromuscular performance in cold environments. Moreover, the nerve conduction rate decreases, the elasticity of the tendons is decreased (Alegre et al. 2016), and if sufficiently cooled, the viscoelastic properties of the synovial 
fluid increase and make joints stiffer (Parsons 2014). All these changes increase the strain on the musculoskeletal apparatus and could increase the risk of overuse injuries like tendinopathy, as has been observed in earlier research (Kurppa et al. 1991; Milgrom et al. 2003). Other acute physiological changes could play a role as well; for example, increased muscle activity to produce heat will increase the load to the muscles and vasoconstriction following cold exposure could limit the distribution of important nutrients to cells not involved in thermogenesis (Parsons 2014).

It could be hypothesised that cold exposure contributes to a sensitisation process. A study of Danish slaughterhouse workers found that those who had the most complaints about the indoor climate, including cold temperature and draught, had a lower pressure pain threshold (Sundstrup et al. 2015).

\section{Strengths and limitations}

One major strength of this study is its prospective design. Another strength is the reasonably high participation rate of Troms $\varnothing 6$ and Troms $\varnothing 7$ (65\% in both), which increases the likelihood that the surveys contain a representative sample of the working population. There was a larger proportion of participants working in a cold environment $\geq 25 \%$ of the time who were lost to follow-up. Further, in a Norwegian cohort study, common health complaints, such as depression and musculoskeletal pain, increased the likelihood of participation in Troms $\varnothing 7$ (Langhammer et al. 2012), which could have biased our results. However, the difference in loss to follow-up was not evident after exclusion of those with missing values in Troms $\varnothing 6$. Thus, the analyses of the imputed datasets are more likely to be biased by loss to follow-up.

Individuals working in a cold environment tend to have more physically demanding work. Other known occupational risk factors for musculoskeletal pain could be unevenly distributed as well, i.e. poor posture or repetitiveness (Neupane et al. 2013). Therefore, our main analyses could be confounded. However, adjusting for occupational codes in the sensitivity analyses did not alter the strength of the association (Supplementary Table 2), making residual confounding by occupational factors less likely. On the other hand, it is possible that even within the same occupational code, those working in a cold environment $\geq 25 \%$ of the time are exposed to a different set of risk factors than those working in a cold environment $<25 \%$ of the time.

As the question about working in a cold environment was not repeated in Troms $\varnothing 7$ we do not know if exposure was consistent between Troms $\varnothing 6$ and Troms $\varnothing 7$. Differences between exposed and non-exposed participants could have increased the probability of them changing occupations or exiting the work force, either due to health or changes in the labour market. If working in a cold environment in Troms $\varnothing 6$ caused or aggravated pain, it is possible that some participants ended their exposure to reduce the risk of pain before Troms $\varnothing 7$. In addition, the youngest participant in Troms $\varnothing 6$ was 32 years of age, thus participants might have been exposed for over 10 years before even entering the study, and those most easily affected by a cold environment might already have developed MSC in Troms $\varnothing 6$. Furthermore, they might have changed occupation prior to Troms $\emptyset 6$ to reduce their exposure, and in turn, their risk of developing or aggravating existing MSC. Consequently, we might have underestimated the possible effect of cold environment due to the healthy-worker effect.

There are several diseases that probably increase the risk of developing MSC (Treede et al. 2015). These could be unevenly distributed between those working in a cold environment $\geq 25 \%$ of the time and those that do not. The lack of adjusting for these conditions is a limitation. However, we adjusted for self-reported health, which is thought to be a very inclusive measure of health (Mackenbach et al. 2002). Further, the origin of pain can be difficult to determine, and even though the participants were asked for pain and/ or stiffness in muscles or joints, we cannot be sure that the complaints did not have other origins (Treede et al. 2015).

Troms $\varnothing$ is situated at $69^{\circ}$ North, but has a moderately cold climate due to the Gulf Stream. The cold exposure is dependent on many factors other than ambient air temperature, i.e. amount of clothing or contact with cold surfaces or liquids. Thus, we expect that the results are relevant for other workers that are at risk of cold stress.

\section{Conclusion}

Working in a cold environment $\geq 25 \%$ of the time increased the risk of future MSC. The increased risk was small, $15 \%$ after adjustment for possible confounders. There was no significantly increased risk of MSC in $\geq 3$ regions, and no increased risk of severe MSC. However, the crude exposure measurement and the healthy worker effect might have biased the results. There is a need for prospective studies with a more precise measure of exposure.

Author contributions EHF, ACH, and MS designed the study. EHF conducted the data analysis and wrote the manuscript with the assistance of ACH and MS. TB assisted in the analysis. All authors contributed to the interpretation and revised the manuscript. All authors read and approved the final manuscript.

Funding Open Access funding provided by UiT The Arctic University of Norway. This particular study has been funded by UiT-The Arctic University of Norway. The sixth and seventh survey of the Troms $\varnothing$ Study is a collaboration between the Northern Norway Regional Health Authority, UiT-The Arctic University of Norway, Norwegian Ministry of Health and Care Services, Troms County, and the Norwegian Institute of Public Health. 
Code availability All statistical analyses were performed in Stata MP 15 .

Data availability All data are available by applying to the Troms $\varnothing$ Study https://tromsoundersokelsen.uit.no/tromso

\section{Compliance with ethical standards}

Conflict of interest The authors declare that they have no conflict of interest.

Ethics approval The Regional Committee of Research Ethics approved Troms $\varnothing 6$ and 7 and this particular analysis.

Consent to participate Informed consent was obtained from all individual participants included in the study.

Open Access This article is licensed under a Creative Commons Attribution 4.0 International License, which permits use, sharing, adaptation, distribution and reproduction in any medium or format, as long as you give appropriate credit to the original author(s) and the source, provide a link to the Creative Commons licence, and indicate if changes were made. The images or other third party material in this article are included in the article's Creative Commons licence, unless indicated otherwise in a credit line to the material. If material is not included in the article's Creative Commons licence and your intended use is not permitted by statutory regulation or exceeds the permitted use, you will need to obtain permission directly from the copyright holder. To view a copy of this licence, visit http://creativecommons.org/licenses/by/4.0/.

\section{References}

Aasmoe L, Bang B, Egeness C, Lochen ML (2008) Musculoskeletal symptoms among seafood production workers in North Norway. Occup Med (Lond) 58:64-70

Alegre LM, Hasler M, Wenger S, Nachbauer W, Csapo R (2016) Does knee joint cooling change in vivo patellar tendon mechanical properties? Eur J Appl Physiol 116:1921-1929. https://doi. org/10.1007/s00421-016-3444-5

Bang BE et al (2005) Feeling cold at work increases the risk of symptoms from muscles, skin, and airways in seafood industry workers. Am J Ind Med 47:65-71. https://doi.org/10.1002/ajim.20109

Bergman S, Herrstrom P, Jacobsson LT, Petersson IF (2002) Chronic widespread pain: a three year follow-up of pain distribution and risk factors. J Rheumatol 29:818-825

Burstrom L, Jarvholm B, Nilsson T, Wahlstrom J (2012) Back and neck pain due to working in a cold environment: a cross-sectional study of male construction workers. Int Arch Occup Environ Health. https://doi.org/10.1007/s00420-012-0818-9

Burstrom L, Jarvholm B, Nilsson T, Wahlstrom J (2013) Back and neck pain due to working in a cold environment: a cross-sectional study of male construction workers. Int Arch Occup Environ Health 86:809-813. https://doi.org/10.1007/s00420-012-0818-9

Dovrat E, Katz-Leurer M (2007) Cold exposure and low back pain in store workers in Israel. Am J Ind Med 50:626-631. https://doi. org/10.1002/ajim.20488

Elliott AM, Smith BH, Hannaford PC, Smith WC, Chambers WA (2002) The course of chronic pain in the community: results of a 4-year follow-up study. Pain 99:299-307. https://doi.org/10.1016/ s0304-3959(02)00138-0
Farbu EH, Skandfer M, Nielsen C, Brenn T, Stubhaug A, Höper AC (2019) Working in a cold environment, feeling cold at work and chronic pain: a cross-sectional analysis of the Troms $\emptyset$ Study. BMJ Open 9:31248. https://doi.org/10.1136/bmjopen-2019-031248

Gasparrini A et al (2015) Mortality risk attributable to high and low ambient temperature: a multicountry observational study. Lancet 386:369-375. https://doi.org/10.1016/s0140-6736(14)62114-0

Haukka E et al (2015) Multisite musculoskeletal pain predicts medically certified disability retirement among Finns. Eur J Pain 19:1119-1128. https://doi.org/10.1002/ejp.635

ISO 15743:2008 (2008) Ergonomics of the thermal environmentcold workplaces-risk assessment and managment. International Organization of Standardisation, Geneva

Jacobsen BK, Eggen AE, Mathiesen EB, Wilsgaard T, Njolstad I (2012) Cohort profile: the Tromso Study. Int J Epidemiol 41:961-967. https://doi.org/10.1093/ije/dyr049

Kurppa K, Viikari-Juntura E, Kuosma E, Huuskonen M, Kivi P (1991) Incidence of tenosynovitis or peritendinitis and epicondylitis in a meat-processing factory. Scand J Work Environ Health 17:32-37

Langhammer A, Krokstad S, Romundstad P, Heggland J, Holmen J (2012) The HUNT study: participation is associated with survival and depends on socioeconomic status, diseases and symptoms. BMC Med Res Methodol 12:143. https://doi. org/10.1186/1471-2288-12-143

Langley P, Muller-Schwefe G, Nicolaou A, Liedgens H, Pergolizzi J, Varrassi G (2010) The impact of pain on labor force participation, absenteeism and presenteeism in the European Union. J Med Econ 13:662-672. https://doi.org/10.3111/13696998.2010.529379

Mackenbach JP, Simon JG, Looman CW, Joung IM (2002) Selfassessed health and mortality: could psychosocial factors explain the association? Int J Epidemiol 31:1162-1168. https://doi. org/10.1093/ije/31.6.1162

Makinen TM, Hassi J (2009) Health problems in cold work. Ind Health 47:207-220. https://doi.org/10.2486/indhealth/47.207

Milgrom C, Finestone A, Zin D, Mandel D, Novack V (2003) Cold weather training: a risk factor for Achilles paratendinitis among recruits. Foot Ankle Int 24:398-401

Murray CJL et al (2012) Disability-adjusted life years (DALYs) for 291 diseases and injuries in 21 regions, 1990-2010: a systematic analysis for the global burden of disease study. Lancet 380:21972223. https://doi.org/10.1016/S0140-6736(12)61689-4

Neupane S, Miranda H, Virtanen P, Siukola A, Nygård C-H (2013) Do physical or psychosocial factors at work predict multi-site musculoskeletal pain? A 4-year follow-up study in an industrial population. Int Arch Occup Environ Health 86:581-589. https:// doi.org/10.1007/s00420-012-0792-2

Neupane S et al (2018) Multisite musculoskeletal pain trajectories from midlife to old age: a 28-year follow-up of municipal employees. Occup Environ Med 75:863-870. https://doi.org/10.1136/oemed $-2018-105235$

Parsons K (2014) Human thermal environments: the effects of hot, moderate, and cold environments on human health, comfort, and performance. CRC Press Inc., Boca Rotan

Pienimaki T (2002) Cold exposure and musculoskeletal disorders and diseases. A review. Int J Circumpolar Health 61:173-182

Racinais S, Oksa J (2010) Temperature and neuromuscular function. Scand J Med Sci Sports 20(Suppl 3):1-18. https://doi.org/10.111 1/j.1600-0838.2010.01204.x

Saastamoinen P, Laaksonen M, Kääriä S-M, Lallukka T, Leino-Arjas P, Rahkonen O, Lahelma E (2012) Pain and disability retirement: a prospective cohort study. Pain 153:526-531. https://doi. org/10.1016/j.pain.2011.11.005

Skandfer M, Talykova L, Brenn T, Nilsson T, Vaktskjold A (2014) Low back pain among mineworkers in relation to driving, cold 
environment and ergonomics. Ergonomics 57:1541-1548. https ://doi.org/10.1080/00140139.2014.904005

Smidt N, van der Windt DAWM, Assendelft WJJ, Devillé WLJM, Korthals-de Bos IBC, Bouter LM (2002) Corticosteroid injections, physiotherapy, or a wait-and-see policy for lateral epicondylitis: a randomised controlled trial. Lancet 359:657-662. https ://doi.org/10.1016/S0140-6736(02)07811-X

Sundstrup E, Jakobsen MD, Brandt M, Jay K, Persson R, Andersen LL (2015) Central sensitization and perceived indoor climate among workers with chronic upper-limb pain: cross-sectional study. . Pain Res Treat 2015:793750. https://doi.org/10.1155/2015/793750

Treede RD et al (2015) A classification of chronic pain for ICD-11. Pain 156:1003-1007. https://doi.org/10.1097/j.pain.0000000000 000160
Weather statistics for Troms $\varnothing$ observation site, Troms $\emptyset$ (Troms) (2018) The Norwegian Meteorological Institute. https://www.yr.no/place /Norway/Troms/Troms\%C3\%B8/Troms\%C3\%B8_observation_ site/statistics.html. Accessed 13 Nov 2018

Zou G (2004) A modified Poisson regression approach to prospective studies with binary data. Am J Epidemiol 159:702-706. https:// doi.org/10.1093/aje/kwh090

Publisher's Note Springer Nature remains neutral with regard to jurisdictional claims in published maps and institutional affiliations. 